\title{
The pursuit of perfect control in diabetes
}

\author{
Better insulin better delivered
}

There are many reasons why subcutaneous injections of insulin do not produce metabolic normality in patients with diabetes. The slow absorption of insulin given subcutaneously means that glucose concentrations rise excessively at meal times and then are followed by hypoglycaemia, the erratic absorption of insulin produces unpredictable glycaemic control, and the lack of automatic feedback means that insulin is not delivered according to the prevailing glucose concentrations. Furthermore, many patients with diabetes find multiple insulin injections and their complications, such as lipodystrophy, unacceptable. There is thus good reason to try to improve treatment with insulin, and several promising approaches are being developed, though only a few are being used in routine clinical practice. All components of the system of delivering insulin are being attacked-that is, the insulin itself, the apparatus for giving insulin, the route of entry to the body, and the absorption process.

Most of the insulin in pharmaceutical preparations is in the form of hexamers. Postulating that monomeric insulin may be absorbed more quickly from the subcutaneous site, Brange et al made several insulin analogues by recombinant DNA technology in which single amino acids were substituted at sites important in the interaction between monomers but peripheral to the region of receptor binding. ' In most cases a negatively charged amino acid was inserted so that charge repulsion inhibited association between the monomers. Most of the analogues made by Brange et al retained most of the biological activity of native insulin, but the subcutaneous rates of absorption of the analogues were two to three times faster than those for conventional short acting insulin.

Protein engineering has also been used to produce a range of soluble long acting insulins. The isoelectric point of insulin (where the protein is most insoluble) was moved in these studies from $5 \cdot 4$ towards neutral values. This was achieved by using tryptic transpeptidation to substitute basic amino acids at the terminus of the $\mathrm{B}$ chain ${ }^{2}$ or site specific mutagenesis to replace amino acids elsewhere in a single chain insulin precursor produced by genetic engineering techniques, which was later converted to two chain insulin. ${ }^{3}$ When slightly acid solutions of these insulins are injected they crystallise readily in the tissues at neutral $\mathrm{pH}$ and have appreciably delayed absorption. Acid solutions of insulin are, however, unstable, and Markussen $e t$ al have introduced substitutions to improve stability. ${ }^{+}$The variation in the subcutaneous absorption of at least one of these analogues from day to day is about half that of conventional crystal suspensions, and the half life for absorption is about 25 hours.

These "designer insulins" must now undergo trials to study immunogenicity and possible unwanted metabolic effects, but they hold exciting possibilities for improving glycaemic control.

Modified insulins of a different type are being investigated as self regulating delivery systems based on the competitive binding of glucose and glycosylated insulin to the lectin concanavalin A. Brownlee and Cerami originally proposed this approach using insulins conjugated with maltose and other oligosaccharides, ${ }^{56}$ and Sato et al have reported several glycosylated derivatives with different binding constants encapsulated with the lectin in a polymer membrane permeable to glucose. ${ }^{7}$ Two derivatives $-p$-(succinylamido) phenyl- $\alpha$ D-mannopyranoside-insulin and $p$-(succinylamido) phenyl- $\alpha$ D-glucopyranoside insulin - are showing promise in retaining biological activity, being less liable than native insulin to aggregate, and in exhibiting glucose dependent displacement of insulin from the device.

Polymer systems have been used in several ways for the controlled release of insulin. Biodegradable polymers containing drugs have the particular advantage of not requiring the removal of the spent device; polyanhydrides are one of the favoured materials as they are biocompatible, non-toxic, and erode from the surfaces, so that release is more controllable. Polyanhydride microspheres containing insulin are injectable, and have been used in recent preliminary studies to control diabetes over several days in rats. ${ }^{8}$

Release of insulin from discs of non-degradable polymers such as vinyl acetate-ethylene is constant in vitro and maintains good control in diabetic rats when the discs are implanted in the subcutaneous tissue. ${ }^{9}$ Modulated insulin delivery might be achieved from such systems by incorporating magnetic beads along with the insulin and polymer matrix and subjecting the system to an external oscillating magnetic field. ${ }^{10} \mathrm{~A}$ similar approach has been outlined for insulin incorporated in alginate microspheres loaded with fernites: they show a 50 -fold increase in the rate of release of insulin when a magnetic field is applied. ${ }^{11}$

Glucose controlled release of insulin from polymers was proposed by Ishihara et al, who described a complex membrane consisting of immobilised glucose oxidase and an adjoining polyamine membrane. ${ }^{12}$ Oxidation of glucose to gluconic acid protonated the membrane, increased the 
swelling of the membrane, and thus reversibly augmented the permeability to insulin. More recently an equally ingenious notion has been reported in which glucose oxidase is incorporated in a polymer matrix with trilysyl insulin, which has a raised isoelectric point of $7 \cdot 4 \cdot{ }^{13}$ Exposure to glucose decreases the $\mathrm{pH}$, which increases both the solubility and the release of insulin.

Continuous subcutaneous infusion of insulin from a portable pump is currently used in routine practice as an alternative form of intensified insulin treatment, ${ }^{14}$ but because of the cost and the need for supervision and commitment by the patient it is suitable for comparatively few patients. Equally strict control may be achieved in many patients by multiple insulin injections, and acceptance of these regimens has been increased by the new "pens" that contain a prefilled cartridge of insulin and an integral needle for easy injection. ${ }^{15}$

The recent policy statement of the American Diabetes Association on needleless jet injectors concluded that there was insufficient information about their benefits and risks to make recommendations on their use. ${ }^{16}$ Independent trials are needed to identify the best jet injector regimens, the frequency of possible complications such as hypoglycaemia and the formation of antibodies to insulin caused by denatured insulin, and the cost of treatment.

Developments in continuous subcutaneous insulin infusion centre on trying to identify patients most likely to stop the treatment ${ }^{17}{ }^{18}$ (often young women with a history of frequent antecedent episodes of ketoacidosis), increasing patient acceptability by introducing smaller, less complex infusers, and studying and perhaps rectifying the changes that occur in the counter regulatory responses and the recognition of hypoglycaemia during treatment with pumps. There is increasing evidence that the glycaemic threshold for releasing adrenaline and adrenaline's circulating concentration at any given concentration of glucose are lowered by good diabetic control, thus increasing the risk of hypoglycaemia. ${ }^{19}$

Over 200 insulin pumps have been implanted into patients with diabetes. Most of the pumps have been the constant rate, vapour powered Infusaid device..$^{20} 21$ About half of the patients have received the insulin intravenously and half intraperitoneally. The most recent and advanced device to undergo clinical trial is the programmable implantable medication system (PIMS), which allows remote programming and interrogation by radio telemetry or telephone communication. ${ }^{22}$ A continuing problem has been the tendency for conventional insulin to form insoluble, non-covalent, fibrillar aggregates in the pump reservoirs. ${ }^{23}$ This aggregation is initiated mainly by the prolonged exposure to body heat, movement, and contact with hydrophobic surfaces. More stable insulins have been suggested with various additives, including glycerol and bicarbonate ${ }^{25}$ and surfactants such as polyethylene polypropylene glycol. ${ }^{26}$ Insulin analogues such as the monomers produced by protein engineering have not yet been tested in implanted delivery systems. Another important problem with at least some implanted pumps has been intraperitoneal blockage of the infusion cannula with omental tissue. ${ }^{27}$

Progress in passing feedback to insulin pumps through an implanted glucose sensor has been hampered by the unpredictable drift of enzyme electrodes and their sensitivity to fluctuating oxygen tension at the implantation site.$^{28}$ Attempts are being made to overcome these problems with special configurations of the covering membranes, ${ }^{29}$ improved immobilisation of the enzyme, ${ }^{30}$ and the incorporation of redox mediators such as ferrocene to shuttle electrons directly to the electrode rather than to oxygen. ${ }^{31}$

The alternative route of insulin delivery that has caused the most recent interest is the nasal mucosa. Adjuvants such as bile salts ${ }^{32}$ and the surfactant laureth $9^{33}$ are necessary to promote nasal absorption of insulin from aerosols. How they work is uncertain, but possibilities include the formation of insulin monomers and polar lined channels in the nasal cell membranes through which the monomers may be transported $^{32}$ and the enlargement of intercellular gaps. ${ }^{3+}$ Intranasal insulin is rapidly absorbed, ${ }^{33}$ and thus it is good for controlling glycaemia related to meals, though large doses are required (often over 100 units before each meal). Clinical trials of preprandial nasal insulin combined with subcutaneous injection of ultralente insulin ${ }^{35}$ and basal insulin given by continuous subcutaneous insulin infusion ${ }^{36}$ have not shown any improvement in glycaemic control when compared with an entirely subcutaneous regimen - and often the control is worse. The potential interference of allergic rhinitis, upper respiratory tract infections, and any nasal irritation caused by the preparations also awaits further study.

I hope that many of these promising ideas for insulin delivery will soon progress from feasibility studies in animals to clinical trials in patients with diabetes. If they do the prospects are good for more physiological profiles of insulin and glucose in diabetes.

JOHN PICKUP

Reader,

Division of Chemical Pathology,

United Medical and Dental School of Guy's and St Thomas's Hospitals, Guy's Hospital,

London SE1 9RT

Brange J, Ribel U, Hansen JF, et al. Monomeric insulins obtained by protein engineering and thei medical implications. Nature 1988;333:679-82.

Markussen J, Hougaard P, Ribel U, Sorensen AR, Sorensen E. Soluble, prolonged-acting insulin derivatives. I. Degree of protraction and crystallizability of insulins substituted in the termini of the B-chain. Protein Engineering 1987;1:205-13.

3 Markussen J, Diers I, Engesgaard A, et al. Soluble, prolonged-acting insulin derivatives. II. Degree of protraction and crystallizability of insulins substituted in positions A17, B8, B13, B27 and B30. Protein Engineering 1987;1:215-23.

4 Markussen J, Diers I, Hougaard P, et al. Soluble, prolonged-acting insulin derivatives. III. Degree of protraction, crystallizability and chemical stability of insulin substituted in positions A21, of protraction, crystallizability and chemical stability of insu
B13, B23, B27 and B30. Protein Engineering 1988;2:157-66.

5 Brownlee M, Cerami A. A glucose-controlled insulin-delivery system: semi synthetic insulin bound to lectin. Science 1979;206:1190-1.

6 Brownlee M, Cerami A. Glycosylated insulin complexed to Con A. Diabetes 1983;32:499-504

Sato S, Yeong SY, McRea JC, Kim SW. Self-regulating insulin delivery systems. II. In vitro studies. Fournal of Controlled Release 1984;1:67-77.

8 Mathiowitz E, Langer R. Polyanhydride microspheres as drug carriers. I. Hot-melt microencap sulation. Fournal of Controlled Release 1987;5:13-22.

Brown L, Munoz C, Siemer L, Edelman E, Langer R. Controlled release of insulin from polyme matrices. Control of diabetes in rats. Diabetes 1986;35:692-7.

10 Kost J, Wolfrum J, Langer R. Magnetically enhanced insulin release in diabetic rats. $\mathcal{F}$ Biomed Mater Res 1987:21:1367-73.

11 Saslawski $O$, Weingarten C, Benoit JP, Couvreur P. Magnetically responsive microspheres for the pulsed delivery of insulin. Life Sciences 1988;42:1521-8.

12 Ishihara $\mathrm{K}$, Kobayashi M, Ishimaru N, Shinohara I. Glucose induced permeation control of insulin through a complex membrane consisting of immobilised glucose oxidase and a (poly)amine. Polymer foumal 1984;16:625-31.

13 Fischel-Ghodsian F, Brown L, Mathiowitz E, Bradenburg D, Langer R. Enzymatically controlled drug delivery. Proc Natl Acad Sci USA 1988;85:2403-6.

14 Pickup J. Indications, contraindications and complications of continuous subcutaneous insulin infusion. In: Serrano-Rios M, Lefebvre PJ, eds. Diabetes 1985. Amsterdam: Elsevier, 1986: 900-3.

15 Saubrey N, Arnold-Larsen S, Moller-Jensen B, Kuhl C. Comparison of continuous subcutaneou insulin infusion with multiple insulin injections using the Novopen. Diabetic Med 1988;5:150-3.

16 American Diabetes Association. Position statement on jet injectors. Diabetes Care 1988;11:600-1

17 Bell DSH, Ackerson C, Cutter G, Clements RS. Factors associated with discontinuation of continuous subcutaneous insulin infusion. Am f Med Sci 1988;295:23-8.

18 Guinn TS, Bailey GJ, Mecklenburg RS. Factors related to discontinuation of continuous subcutaneous insulin infusion therapy. Diabetes Care 1988;11:46-51.

19 Amiel S, Sherwin RS, Simonson DC, Tamborlane WV. Effect of intensive insulin therapy on glycemic thresholds for counterregulatory hormone release. Diabetes 1988;37:901-7.

20 Buchwald H, Chute EP, Rupp WM, et al. Implantable infusion pump for insulin delivery: past, present and future. Life Support Syst 1985;3:51-3.

$21 \mathrm{Kritz} \mathrm{H}$, Hagmuller G, Lovett R, Irsigler K. Implanted constant basal rate insulin infusion devices for type I (insulin-dependent) diabetic patients. Diabetologia 1983;25:78-81.

22 Saudek CD Pitt HA Dempsey $M$, et al. The programmable implantable medication system (PIMS): first human implantations. Diabetes 1987;36(suppl 1):77A.

23 Longheed WD, Woulfe-Flanagan H, Clement JR, Albisser AM. Insulin aggregation in artificial delivery systems. Diabetologia 1980;19:1-y.

24 Brange J, Havelung S. Insulin pumps and insulin quality-requirements and problems. Acta Med Scand [Suppl] 1983;671:135-8.

25 Blackshear PJ, Rohde TD, Palmer JL, Wigness BD, Rupp WM, Buchwald H. Glycerol prevents insulin precipitation and interruption of flow in an implantable insulin infusion pump. Diabetes Care 1983;6:387-92.

26 Grau U, Saudek CD. Stable insulin preparation for implanted insulin pumps. Laboratory and animal trials. Diabetes 1987:36:1453-9.

27 Zinman B. Santiago JV. Devices and strategies for diabetes management. In: Second world conference on diabetes research: New York: Juvenile Diabetes Foundation International, 1988: conferenct
$52-7$.

28 Turner APF, Pickup JC. Diabetes mellitus: biosensors for research and management. Biosensors $1985 ; 1: 85-115$. 
29 Gough DA, Lucisano JV, Tse PHS. Two-dimensional enzyme electrode sensor for glucose. Anal Chem 1985;57:2351-7.

30 Pickup JC, Shaw GW, Claremont DJ. Potentially-implantable, amperometric glucose sensors with mediated electron transfer: improving the operating stability. Biosensors (in press).

31 Claremont DJ, Sambrook IE, Penton C, Pickup JC. Subcutaneous implantation of a ferrocenemediated glucose sensor in pigs. Diabetologia 1986;29:817-21.

32 Gordon GS, Moses AC, Silver RD, Flier JS, Carey MC. Nasal absorption of insulin: enhancement by hydrophobic bile salts. Proc Natl Acad Sci USA 1985;82:7419-23.
33 Salzman R, Manson JE, Griffing GT, et al. Intranasal aerosolized insulin. Mixed meal studies and long-term use in type 1 diabetes. $N$ Engl f Med 1985;312:1078-84.

4 McMartin C, Hutchinson LEF, Hyde R, Peters GE. Analysis of structural requirements for the absorption of drugs and macromolecules from the nasal cavity. F P harm Sci 1987;76:535-40.

5 Frauman AG, Cooper ME, Parsons BJ, Jerums G, Louis WJ. Long-term use of intranasal insulin in insulin-dependent diabetic patients. Diabetes Care 1987;10:573-8.

36 Lassman-Vague V, Thiers D, Vialettes B, Vague P. Preprandial intranasal insulin. Lancet $1988 ; \mathrm{i}: 367-8$.

\title{
Junior hospital doctors: tired and tested
}

\author{
Should the rules for pilots apply to doctors?
}

Few people will be surprised that a paper to be published soon in the $B M \mathcal{F}$ will show cognitive impairment and mood changes in junior doctors working long hours. We would expect such findings in subjects deprived of sleep from other walks of life, and we might condemn their work schedules, but doctors have traditionally felt free to ignore the advice they give to others. Recently, however, interest in whether tired doctors might be dangerous has reached a level that is difficult to ignore, and the BMA's annual meeting has called for limits on the hours that junior staff work (16 July, p 217).

Those doctors who consider that the houseman's year is a necessary evil, a rite, or even an advantageous education ${ }^{12}$ might reasonably ask whether reduced performance on cognitive tests automatically implies reduced medical ability. Research on this subject, although sparse, goes back a long way, and the chance findings of Poulton et al in 1978 are a good example of how mixed the results may be. ${ }^{3}$ In their study on doctors deprived of sleep they found that performance of a grammatical reasoning task was significantly different if the test was immediately followed by a second task of sorting laboratory results into normal and abnormal. Those doctors who did only the grammatical reasoning task showed a reduced performance once they had accumulated three hours of sleep deficit (over the previous one to three days), whereas those who did both tests showed no decline in their performance until their sleep deficit reached eight hours. ${ }^{3}$

That the research findings may be confusing is not surprising. We all know that we perform poorly if we are almost asleep, but neither are we at our best when overexcited or panicking. Somewhere in between is the "optimum level of arousal," originally described in the inverted U curves of Yerkes and Dodson in $1908 .{ }^{+}$Factors that shift our arousal up or down abound in the environment as well as within ourselves. The effect of noise and heat, for example, are well described $^{5}$ as are those of natural circadian rhythms ${ }^{6}$ and coffee. ${ }^{7}$ There are also influences from the tasks performed: the duration of the task, ${ }^{8}$ feedback on performance, ${ }^{8}$ standards of performance learnt at the time the task itself was learnt, ${ }^{3}$ and the complexity of the $\operatorname{task}^{9}$ are all important. Even when factors such as these have been carefully balanced out in the experimental design there is still the uncomfortable feeling that arousal may be partly under volitional control. Several studies have shown that motivation has a strong influence on performance. ${ }^{9-11}$

Despite this multitude of variables there is a considerable consensus on the effects of long work hours and reduced sleep-at least in the laboratory. In general, the earliest changes are fatigue and alterations of mood. These effects should not be ignored as they may influence interpersonal relationships and the efficiency of a team. Detectable changes in individual performance appear later, and Nicholson and Stone summarise these in saying "the effects of sleep loss vary widely. .. Interesting tasks with relatively simple motor skills are resistant for periods as long as 60 hours, but routine monotonous tasks show a rapid and severe decrement after 18 hours without sleep.... Sleep deprivation leads to brief intermittent lapses in performance which increase in frequency and duration, and so impaired performance involves missed signals and errors of omission."

So how do people doing real jobs perform when tired? Evidence from aviation and military workers shows that real tasks may be less affected than simulated tasks - for example, one night's loss of sleep had a greater effect on flying a simulator than on flying a real aircraft, although both were significantly affected. ${ }^{13}$ Many of the real world studies might be less sensitive than laboratory studies because of the problems of experimental control, but different degrees of motivation are probably also important.

If performance at a genuine job tends to be preserved then this might explain why there have been so few reports of tired doctors giving inadequate care. An alternative explanation is that such cases may be underreported. The Civil Aviation Authority fund the Royal Air Force Institute of Aviation Medicine to run a confidential human factors incident reporting programme, to which any pilot or air traffic controller may write without fear of identification or disciplinary action. About a third of the incidents reported result from sleep, fatigue, or rostering, and many could easily have been accidents. ${ }^{14}$ Although there have been few aircraft accidents actually attributed to fatigue, it would be foolish to assume that fatigue does not affect pilots. Is it not then foolish to assume that fatigue does not affect junior doctors?

The differences in the rules for pilots and doctors are interesting ( $p$ 938). In most cases the duty periods of pilots are limited to eight to 14 hours. Aircraft captains may use their discretion to increase this on special occasions, and extensions may also apply if crew members are able to take rest in flight. If a bunk is available, for example, the flying duty period may be increased by half the time spent in the bunk - to a maximum of 18 hours total duty. After any flying duty aircrew must rest for at least 12 hours, and the rest must not be shorter than the preceding duty period. ${ }^{15}$ In comparison, about two thirds of junior doctors work rotas of one in two or one in three-and $5 \%$ of those on call all night work without a break from midnight to $8 \mathrm{am}$ as well as working the day shifts each side. ${ }^{16}$

Both flying and medicine are unforgiving of seemingly minor slips. Although fatigued staff may perform surprisingly well at a motivating challenge, they are likely to make an increasing number of minor errors in subsidiary tasks. A wrong decimal point, a forgotten drug interaction, or incorrect labelling of right or left and the results may be catastrophic. To reduce the hours worked by junior doctors, on the other hand, may be difficult and unpopular as it would imply an 